\title{
Successful pregnancy in a woman with systemic sclerosis while taking nifedipine
}

\author{
A G McT Wilson, J D T Kirby
}

\begin{abstract}
The case is reported of successful conception and pregnancy in a woman with systemic sclerosis while receiving continuous treatment with nifedipine $30 \mathrm{mg} / \mathrm{day}$, after a previously poor obstetric record and involuntary secondary infertility.
\end{abstract}

There is limited experience of pregnancy in women with systemic sclerosis because systemic sclerosis is itself an uncommon condition (4.5-12 new cases per million population per year). ${ }^{1}$ The peak onset is in the third to fifth decades and there is possible secondary infertility.

There is also little experience of the use of nifedipine during the first trimester of pregnancy. Only six cases in which the outcome is known have been reported to the manufacturer, Bayer (UK). In later pregnancy it has been shown to be effective in both acute and chronic pregnancy associated hypertension, ${ }^{23}$ and also as a tocolytic agent in the treatment of premature labour. ${ }^{4}$ Recently, it has been shown to have beneficial effects on abnormal blood coagulation, in particular the prolonged thrombolysis found in patients with systemic sclerosis.

\section{Case report}

The patient, a 36 year old white woman, was diagnosed as having systemic sclerosis when aged 15 on clinical grounds (Raynaud's phenomenon, sclerodactyly, impaired finger flexion, loss of finger pulp substance, dysphagia, and telangiectasia). (Serology: antinuclear antibodies positive $1 / 160(100 \mathrm{IU} / \mathrm{ml})$, anti-dsDNA negative, RNP positive, latex positive $1 / 40$, RAHA positive $1 / 40$, Scl 70 negative, Ro negative, La negative, $\mathrm{Sm}$ negative, cryoglobulins negative.) She had been a cigarette smoker and had taken the contraceptive pill (ethinyloestradiol $30 \mu \mathrm{g}$ ) for five years.

Despite bilateral cervical sympathectomy her Raynaud's phenomenon resulted in digital ulceration, requiring amputation of the left index and middle fingers. Her other main problem was painful, intractable foot ulceration associated with smooth, atrophic, ivory-white scars surrounded by pigmentation and ectatic blood vessels (atrophie blanche, livedoid vasculitis) since the age of 19 . The foot ulcers were refractory to both outpatient and inpatient treatment and required pinch skin grafting on four occasions. Doppler ultrasound arterial pressures in the legs were normal both at rest and after exercise. There was no evidence of venous incompetence. Previous treatment included aspirin, oil of evening primrose, and three eight hour infusions of the prostacyclin analogue, Iloprost. Measurement of her blood coagulation was carried out with a newly designed instrument, the haemostatometer. ${ }^{6}$ Briefly, samples of heparinised and nonheparinised blood were perfused through two polyethylene tubes within a closed pressure system. A standard sized hole was punched into each tube allowing 'bleeding' and a consequent fall in pressure. Non-heparinised blood formed $a^{*}$ platelet plug and ultimately clotted. In the heparinised channel clotting was prevented. Haemostatic platelet plug formation and thrombolysis, resulting in weakening and expulsion of the haemostatic plug, were detected as changes in pressure, and the timing of these events was recorded. The time taken to achieve $30 \%$ of haemostatic plug information (HPF-30) was a good index of platelet function alone. Results for our patient showed that before she was pregnant she had markedly hyperactive platelets and no measurable spontaneous thrombolysis. The HPF-30 was $57 \cdot 9 \%$ of the normal mean. No thrombolysis was measured after 3600 seconds (normal mean 1804.9 (SD 884.5 seconds), after which spontaneous thrombolysis does not take place. Repeat measurements made while receiving nifedipine $60 \mathrm{mg} /$ day showed a spontaneous thrombolysis time of 1566 seconds-that is, within normal limits.

We decided to use nifedipine for treatment of her foot ulceration on the basis of its normalising effect on thrombolysis. We assumed the patient to be secondarily infertile. The nifedipine was increased gradually to $60 \mathrm{mg} /$ day to minimise side effects associated with hypotension in previously normotensive subjects. The foot ulceration became less painful and healed completely within three months. She was taking nifedipine $60 \mathrm{mg} /$ day when she conceived and for a further six weeks until pregnancy was confirmed. The dose of nifedipine was then halved empirically on the basis of the limited information about its effect in pregnancy and maintained at that dose, $30 \mathrm{mg} /$ day, throughout the remainder of the pregnancy. This dose was less effective at maintaining the healing of her foot, however.

\section{PREVIOUS OBSTETRIC HISTORY}

(Gravida 6 para $2+3$ )

1. April 1977: caesarean section 28 weeks for fetal distress. Male $1 \cdot 16 \mathrm{~kg}$ neonatal death.

2. February 1978: miscarriage, 12 weeks. 
3. December 1979: premature labour, 35 weeks. Male $2 \cdot 10 \mathrm{~kg}$ survived.

4. January 1982: missed abortion, 16 weeks.

5. January 1983: ?miscarriage, 6 weeks.

There followed a period of secondary infertility, 1983-1987, during which she attended an infertility clinic, received clomiphene, and underwent five unsuccessful attempts at artificial insemination by husband, AIH.

\section{LATEST PREGNANCY}

Her blood pressure was monitored throughout pregnancy and remained satisfactory. Urine analysis was consistently negative for protein and glucose. Renal function remained within normal limits. Fetal and placental growth were confirmed by serial ultrasound scans. She went into premature labour at 33 weeks' gestation. Initial attempts to halt the progression of the labour were unsuccessful and the labour was allowed to continue: first stage $>24$ hours. She delivered a normal healthy male infant $1.94 \mathrm{~kg}$, who is alive and developing normally.

\section{Discussion}

Giordano et al did not find significant infertility among a series of 86 women with systemic sclerosis when compared with matched controls. ${ }^{7}$ The abortion rate was significantly higher, however, in the patients with systemic sclerosis but not restricted to a few habitual aborters. The case controlled postal questionnaire study of Silman and Black did suggest some reduction in fertility and increased recurrent abortion in women with systemic sclerosis. ${ }^{8}$ The mechanisms of infertility and recurrent spontaneous abortion are not known.

Our patient showed a notable reversal in her obstetric fortunes while taking nifedipine. This might have been fortuitous, but we believe nifedipine might have had a beneficial effect on her conceiving and maintaining the pregnancy, primarily through correction of unfavourable haemostatic abnormalities. Rademaker et al found hyperactive platelet function and prolonged thrombolysis in systemic sclerosis, which was improved by nifedipine. ${ }^{5}$ Our patient showed both these abnormalities, and repeat measurements while taking nifedipine confirmed restoration of normal thrombolysis. Other possible beneficial effects include: ( $a$ ) Primary prevention of hypertension. In both previous pregnancies on completing the second trimester our patient developed pre-eclamptic toxaemia, which did not occur in her latest pregnancy. $(b)$ Prevention of premature labour. Our patient went into labour at 33 weeks despite taking nifedipine. She did experience a prolonged first stage of labour.

Nifedipine used as a tocolytic agent in normotensive women causes a reduction in both systolic and diastolic blood pressures, but these are not significant. ${ }^{4}$ Despite its uterine relaxant properties no patients treated with nifedipine have had excessive uterine bleeding. ${ }^{2}$ The infants had various neonatal problems as would be expected in pregnancies complicated by hypertension, but no adverse effects on the fetus have been reported.

Favourable responses have been reported to treatment of atrophie blanche with antithrombotic drugs, ${ }^{9}{ }^{10}$ those which stimulate fibrinolytic activity, ${ }^{911}$ and haemorheological agents. ${ }^{12}$ There is a previous case report of the use of nifedipine in atrophie blanche. ${ }^{13} \mathrm{We}$ support its use in secondary atrophie blanche associated with systemic sclerosis and suggest that its main effect is to normalise deranged thrombolysis.

We thank Mr M D Simanowitz, consultant obstetrician and gynaecologist, Edgware General Hospital, for permission to report his patient; and Dr I B Kovacs for the coagulation data.

1 Rodnan G P, Jablonska S, Medger T A Jr. Classification and nomenclature of progressive systemic sclerosis (scleroderma). Clin Rheum Dis 1979; 5: 5-13.

2 Walters B N J, Redman C W G. Treatment of severe pregnancy-associated hypertension with the calcium

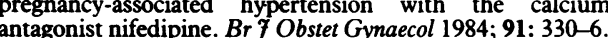

3 Constantine G, Beevers D G, Reynolds A L, Luesley D M Constantine $G$, Beevers D G, Reynolds A L, Luesley D M.
Nifedipine as a second line antihypertensive drug in Nifedipine as a second line antihypertensive drug
pregnancy. Br f Obstet Gynaecol 1987; 94: 1136-42.

4 Read M D, Wellby D E. The use of a calcium antagonis (nifedipine) to suppress preterm labour. $\mathrm{Br} \mathcal{F}$ Obste Gynaecol 1986; 93: 933-7.

5 Rademaker M, Meyrick Thomas RH, Kirby J D T, Kovacs I B. Effects of nifedipine on platelets and thrombolysis in systemic sclerosis. Br f Dermatol 1988; 119 (suppl 33): 25-6.

6 Gorog P. A new, ideal technique to monitor thrombolytic therapy. Angiology 1986; 37: 99-105

7 Giordano M, Valentini G, Lupoli S, Giordano A. Pregnancy and systemic sclerosis. Arthritis Rheum 1985; 28: 237-8.

8 Silman A J, Black C. Increased incidence of spontaneous abortion and infertility in women with scleroderma before disease onset: a controlled study. Ann Rheum Dis 1988; 47: disease

9 Milstone L M, Braverman I M, Lucky P, Fleckman P. Classification and therapy of atrophie blanche. Arch Dermato 1983; 119: 963-9.

10 Yamamoto M, Danno K, Shio H, Imamura S. Antithrombotic treatment in livedo vasculitis. $\mathcal{f}$ Am Acad Dermatol 1988; 18 57-62.

11 Shornick J K, Nicholes B K, Bergstresser P R, Gilliam J N. diopathic atrophie blanche. 7 Am Acad Dermatol 1983; 8 : 792-8.

12 Sams $\mathbb{W}$ M. Livedo vasculitis. Therapy with pentoxifylline. Arch Dermatol 1988; 124: 684-7.

13 Purcell S M, Hayes T H. Nifedipine treatment of idiopathic atrophie blanche. 7 Am Acad Dermatol 1986; 14: 851-4. 